\title{
Antitumor Effect of Liposomal Histone Deacetylase Inhibitor-Lipid Conjugates in Vitro
}

\author{
Yoshiyuki Hattori, ${ }^{*}, a$ Yasuo Nagaoka, ${ }^{b}$ Manami Kubo, ${ }^{a}$ Haruka YAmasaku, ${ }^{a}$ Yuta IshiI,${ }^{b}$ \\ Hiroko OKita, ${ }^{b}$ Hiroki Nakano, ${ }^{b}$ Shinichi Uesato, ${ }^{b}$ and Yoshie Maitani ${ }^{a}$ \\ ${ }^{a}$ Institute of Medicinal Chemistry, Hoshi University; 2-4-41 Ebara, Shinagawa-ku, Tokyo 142-8501, Japan: and ${ }^{b}$ Faculty \\ of Chemistry, Materials and Bioengineering, Kansai University; Suita, Osaka 564-8680, Japan. \\ Received August 2, 2011; accepted August 29, 2011; published online September 7, 2011
}

Histone deacetylase inhibitor (HDACI), suberoylanilide hydroxamic acid (SAHA), approved by the Food and Drug Administration (FDA) for the treatment of cutaneous $T$ cell lymphoma, is a promising new treatment strategy for various cancers. In this study, we hypothesized that a liposomal formulation of HDACI might efficiently deliver HDACI into tumors. To incorporate HDACI efficiently into the liposomal membrane, we synthesized six HDACI-lipid conjugates, in which polyethylene glycol $_{2000}\left(\mathbf{P E G}_{2000}\right)$-lipid or cholesterol (Chol) was linked with a potent hydroxamic acid, HDACI, SAHA or K-182, by cleavable linkers, such as ester, carbamide and disulfide bonds. Liposomal HDACI-lipid conjugates were prepared with distearoylphosphatidylcholine (DSPC) and HDACI-Chol conjugate or with DSPC, Chol and HDACI-PEG-lipid conjugates, and their cytotoxicities were evaluated for human cervix tumor HeLa and mouse colon tumor Colon 26 cells. Among the liposomes, liposomal oleyl-PEG $\mathbf{2 0 0 0}_{\mathbf{2}}$-SAHA conjugated with SAHA and oleyl-PEG $\mathbf{P}_{200}$ via a carbamate linker showed higher cytotoxicity via hyperacetylation of histone $\mathrm{H3}$ and induction of caspase 3/7 activity. These results suggested that liposomal HDACI-lipid conjugates may be a potential tool for cancer therapy.

Key words histone deacetylase inhibitor; suberoylanilide hydroxamic acid; liposome; cytotoxicity

Histone deacetylases (HDAC) are a family of enzymes that have been identified as a promising target to reverse aberrant epigenetic states associated with cancer via the regulation of acetylation levels in histone. ${ }^{1,2)}$ Aberrant histone acetylation has been observed in the development of numerous malignancies, and HDAC inhibitors (HDACIs) are a promising new treatment strategy for malignant disease. ${ }^{3)}$ The hydroxamic acid trichostatin A (TSA) have been known as a differentiation inducer for tumor cells, but its clinical use has been limited by high reactivity and instability. Furthermore, TSA has also been reported to be unstable in vivo following intravenous injection in mice. ${ }^{4,5}$

Suberoylanilide hydroxamic acid (SAHA, vorinostat, Zolinza), is a potent HDACI that has demonstrated antitumor activity in vitro against a variety of cell lines and in vivo against several human tumor xenograft models. ${ }^{6-8)}$ Furthermore, SAHA is currently prescribed to treat cutaneous T-cell lymphoma ${ }^{9)}$ and is also being tested in several phase I to III clinical trials for the treatment of a variety of other cancers, including breast, lung, and colon. ${ }^{10,11)}$ Although SAHA is orally administrated because of its hydrophobic property, it is easily metabolized in the liver. Pharmacokinetic studies in patients after administration of SAHA have identified two inactive metabolites, SAHA-glucuronide and 4-anilino-4oxobutanoic acid, which are pharmacologically inactive, and the mean terminal half-life $\left(t_{1 / 2}\right)$ of SAHA was $c a .2 .0 \mathrm{~h}^{12,13)}$; therefore, the liposomal SAHA formulation warrants in vivo experiments because it allows intravenous administration and prevents metabolism in the liver.

Liposomes have the advantage of an enhanced permeability and retention effect (EPR), increasing their tumor accumulation when they are intravenously injected. ${ }^{14)}$ Such a type of nanocarrier is supposed to improve the pharmacokinetic and pharmacodistribution of the encapsulated drug. Liposomal LAQ824, hydrophilic hydroxamic acid HDACI, was shown to be both long-circulating and highly stable in vivo ${ }^{14)}$; however, in the encapsulation of hydrophobic SAHA into liposome, SAHA must be incorporated into the lipid membrane, which might be limited in its capacity to entrap SAHA. We therefore attempted to synthesize hydroxamatetype HDACI-lipid conjugates as a component of the liposome formulation for efficient incorporation into the liposomal membrane. Previously, we have reported that inclusion of HDACI-lipid conjugates into cationic nanopartilces as a non-viral vector could increase gene expression via hyper acetylation of histone. ${ }^{15)}$ In this study, taking into consideration the diverse derivatization, we selected SAHA and one of the K-series compounds, K-182, which has two OH groups to tether other groups with a biodegradable ester bond, and synthesized cholesteryl HDACI and HDACI-polyethylene glycol (PEG)-lipid conjugates to prepare liposomal HDACIlipid conjugates (Fig. 1). Furthermore, we evaluated their cytotoxic effect on tumor cells via the acetylation of histone $\mathrm{H} 3$ and apoptotic activity.

\section{Experimental}

Synthesis of HDACI-Lipid Conjugates IR spectra were recorded on a Shimadzu FTIR-8400 infrared spectrophotometer. FAB-MS spectra were measured on a JEOL JMS-HX 100 instrument. ${ }^{1} \mathrm{H}$ - and ${ }^{13} \mathrm{C}-\mathrm{NMR}$ spectra were recorded on JEOL EX-400 (399.7 MHz for ${ }^{1} \mathrm{H}-\mathrm{NMR}$ and $100.4 \mathrm{MHz}$ for ${ }^{13} \mathrm{C}$-NMR) instruments using tetramethylsilane as an internal standard. Analytical and preparative TLC were performed using Silica gel 60 F254 (Merck, $0.25,1 \mathrm{~mm}$, respectively) glass plates. Column chromatography was performed using Silica Gel 60 (70-230 mesh ASTM). CM-K-182 was prepared according to the method described previously. ${ }^{15}$ )

Synthesis of Cholest-5-en-3-yl (2R)-2-\{[(9H-Fluoren-9-ylmethoxy)carbonyl]amino $\}-3-\{[(4-m e t h o x y p h e n y l)($ diphenyl)methyl]sulfanyl $\}$ propanoate (2) A solution of Fmoc-Cys (Mmt) -OH (1) (500 mg, 0.81 $\mathrm{mmol}$ ), cholesterol (314 mg, $0.81 \mathrm{mmol}$ ), dimethylaminopyridine (DMAP) (99 $\mathrm{mg}, 0.81 \mathrm{mmol})$ and dicyclohexylcarbodiimide (DCC) (178 mg, $0.81 \mathrm{mmol}$ ) in $\mathrm{CH}_{2} \mathrm{Cl}_{2}(3 \mathrm{ml})$ was stirred at room temperature for $3 \mathrm{~h}$ (Chart 1). After the removal of DCU by filtration, the solution was diluted with $\mathrm{CHCl}_{3}$, washed with $0.1 \mathrm{M} \mathrm{HCl}, 5 \% \mathrm{NaHCO}_{3}$ and saturated $\mathrm{NaCl}$ and then dried over $\mathrm{Na}_{2} \mathrm{SO}_{4}$. Concentration and column chromatography (EtOAc/hexane $=1 / 5)$ gave $2(581 \mathrm{mg}, 72.9 \%)$ as a colorless oil. IR (neat) $\mathrm{cm}^{-1}:$ 3428, 3028, 2951, 2855, 1728, 1669, 700. ${ }^{1} \mathrm{H}-\mathrm{NMR}(399.65 \mathrm{MHz}$, 


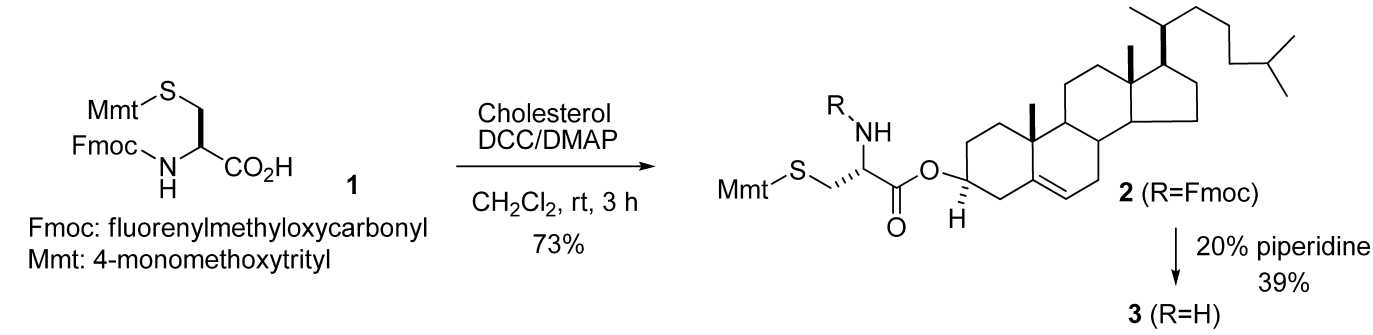

(i) $0.8 \%$ triethylsilane $1 \% \mathrm{CF}_{3} \mathrm{CO}_{2} \mathrm{H}$ $\mathrm{CH}_{2} \mathrm{Cl}_{2}$, rt, $20 \mathrm{~min}$

(ii) DMSO, rt, $2 \mathrm{~h}$ $71 \%$

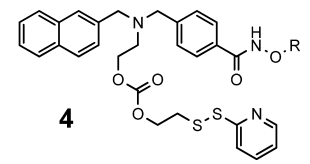

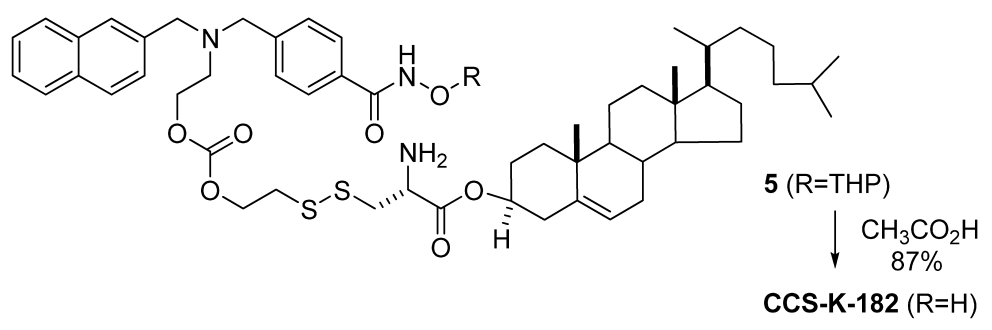

Chart 1. Synthesis Scheme for CCS-K-182

$\left.\mathrm{CDCl}_{3}\right) \delta: 0.68-2.04(44 \mathrm{H}, \mathrm{m}, \mathrm{chol}), 2.30\left(2 \mathrm{H}, \mathrm{m}, \mathrm{S}-\mathrm{CH}_{2}-\mathrm{CH}\right), 2.64(1 \mathrm{H}$, $\mathrm{m}, \mathrm{COO}-\mathrm{CH}), 3.76\left(3 \mathrm{H}, \mathrm{s}, \mathrm{O}-\mathrm{CH}_{3}\right), 4.24\left(1 \mathrm{H}, \mathrm{m}, \mathrm{CH}_{2}-\mathrm{CH}-(\mathrm{Ar})_{2}\right), 4.35$ $\left(2 \mathrm{H}, \mathrm{m}, \mathrm{O}-\mathrm{CH}_{2}-\mathrm{CH}\right), 4.63\left(1 \mathrm{H}, \mathrm{m}, \mathrm{NH}_{2}-\mathrm{CH}-\mathrm{COO}\right), 5.32(1 \mathrm{H}, \mathrm{m}$, $\left.\mathrm{CH}_{2}-\mathrm{CH}-\mathrm{C}\right), 6.80-6.78(2 \mathrm{H}, \mathrm{m}, \mathrm{O}-\mathrm{Ar}-\mathrm{H}), 7.18-7.77(20 \mathrm{H}, \mathrm{m}, \mathrm{Ar}-\mathrm{H})$ ${ }^{13} \mathrm{C}-\mathrm{NMR}\left(100.40 \mathrm{MHz}, \mathrm{CDCl}_{3}\right) \delta: 11.85,14.10,18.70,19.31,21.02,22.55$, $22.64,22.80,23.82,24.27,27.64,28.00,28.21,31.84,31.89,34.32,35.78$, $36.17,36.55,36.87,37.84,39.51,39.71,42.31,47.09,49.97,53.05,55.051$, $56.13,56.67,66.44,67.17,75.66,113.25,119.95,122.98,125.15,126.79$, $127.08,127.70,127.97,129.39,129.42,130.73,136.40,139.31,141.26$, $143.78,143.91,144.60,144.64,155.57,158.21,169.89$. High resolution (HR)-FAB-MS $m / z: 1006.5414$ (Calcd for $\mathrm{C}_{65} \mathrm{H}_{77} \mathrm{NNaO}_{5} \mathrm{~S} \quad\left[\mathrm{M}+\mathrm{Na}^{+}\right]$, 1006.5420)

Synthesis of Cholest-5-en-3-yl (2R)-2-Amino-3-\{[(4-methoxyphenyl)(diphenyl)methyl]sulfanyl $\}$ propanoate (3) A solution of 2 (330 mg, $0.34 \mathrm{mmol})$ in $20 \%$ piperidine $/ \mathrm{CH}_{2} \mathrm{Cl}_{2}(4 \mathrm{ml})$ was stirred at room temperature for $20 \mathrm{~min}$ (Chart 1). The solution was diluted with $\mathrm{CHCl}_{3}$, washed successively with water and saturated $\mathrm{NaCl}$, and then dried over $\mathrm{Na}_{2} \mathrm{SO}_{4}$. Concentration and $\mathrm{SiO}_{2}$ column chromatography $(\mathrm{EtOAc} /$ hexane $=1 / 5)$ gave 3 (101 mg, 39\% yield) as a colorless oil. IR (neat) $\mathrm{cm}^{-1}: 3400,3050,2951$, $2855,1718,1650,701 ;{ }^{1} \mathrm{H}-\mathrm{NMR}\left(399.65 \mathrm{MHz}, \mathrm{CDCl}_{3}\right) \delta: 0.68-1.99(43 \mathrm{H}$, $\mathrm{m}, \mathrm{chol}), 2.25\left(2 \mathrm{H}, \mathrm{m}, \mathrm{CH}-\mathrm{CH}_{2}-\mathrm{C}=\mathrm{CH}\right), 2.49\left(2 \mathrm{H}, \mathrm{m}, \mathrm{S}-\mathrm{CH}_{2}-\mathrm{CH}\right), 3.20$ $\left(1 \mathrm{H}, \mathrm{t}, J=8.6 \mathrm{~Hz}, \mathrm{NH}_{2}-\mathrm{CH}-\mathrm{COO}\right), 3.78\left(3 \mathrm{H}, \mathrm{s}, \mathrm{O}-\mathrm{CH}_{3}\right), 4.52-4.60(1 \mathrm{H}$ $\mathrm{m}, \mathrm{O}-\mathrm{CH}), 5.36-5.36\left(1 \mathrm{H}, \mathrm{m}, \mathrm{CH}_{2}-\mathrm{CH}=\mathrm{C}\right), 6.80-6.82(2 \mathrm{H}, \mathrm{m}$, $\mathrm{O}-\mathrm{Ar}-\mathrm{H}), 7.20-7.43(12 \mathrm{H}, \mathrm{m}, \mathrm{Ar}-\mathrm{H}) ;{ }^{13} \mathrm{C}-\mathrm{NMR}\left(100.40 \mathrm{MHz} \mathrm{CDCl}_{3}\right) \delta$ : $11.85,14.19,18.71,19.31,21.03,22.54,22.80,23.83,24.27,27.65,28.00$, $28.21,31.86,31.89,35.78,36.18,36.56,36.91,37.20,37.93,39.52,39.72$, $42.32,50.01,54.12,55.20,56.15,56.68,60.35,66.37,74.79,113.18$, $122.81,126.66,127.90,129.51,130.80,136.66,139.45,144.91,144.94$, 158.16, 173.23; HR-FAB-MS $m / z$ : 784.4734 (Calcd for $\mathrm{C}_{50} \mathrm{H}_{67} \mathrm{NNaO}_{3} \mathrm{~S}$, 784.4739).

Synthesis of Cholest-5-en-3-yl (13R)-13-amino-1-(2-naphthyl)-6-oxo2-(4-\{[(tetrahydro-2H-pyran-2-yloxy)amino]carbonyl\}benzyl)-5,7-dioxa10,11-dithia-2-azatetradecan-14-oate (5) A solution of $\mathbf{3}(35.1 \mathrm{mg}$, $0.0462 \mathrm{mmol})$, trifluoroacetic acid (TFA) $(16 \mu \mathrm{l})$, and triethylsilane $(20 \mu \mathrm{l})$ in $\mathrm{CH}_{2} \mathrm{Cl}_{2}(2.0 \mathrm{ml})$ was stirred at $0{ }^{\circ} \mathrm{C}$ for $4 \mathrm{~h}$ under Ar atomosphere (Chart 1$)$. After the solution was concentrated in vacuo, the residue was dissolved in dimethyl sulfoxide (DMSO) and to this was added $\left.\mathbf{4}^{15}\right)(30 \mathrm{mg}, 0.069 \mathrm{mmol})$. After stirring for another $2 \mathrm{~h}$ at room temperature, the solution was diluted with $\mathrm{CHCl}_{3}$, washed with water and saturated $\mathrm{NaCl}$, dried over $\mathrm{Na}_{2} \mathrm{SO}_{4}$ and concentrated. Purification with preparative $\mathrm{SiO}_{2}$ thin layer chromatography $($ EtOAc/hexane $=3 / 2)$ gave $5(30 \mathrm{mg}, 71 \%$ yield $)$ as a colorless oil. IR (neat) $\mathrm{cm}^{-1}$ : 3400, 3030, 2935, 2855, 1734, 1684, 699. ${ }^{1} \mathrm{H}-\mathrm{NMR}(399.65 \mathrm{MHz}$, $\left.\mathrm{CDCl}_{3}\right) \delta: 0.67-2.04(53 \mathrm{H}, \mathrm{m}), 2.31-2.33\left(2 \mathrm{H}, \mathrm{d}, J=7.6 \mathrm{~Hz}, \mathrm{SS}-\mathrm{CH}_{2}-\right.$ $\mathrm{CH}), 2.81\left(2 \mathrm{H}, \mathrm{t}, J=8.4 \mathrm{~Hz}, \mathrm{~N}-\mathrm{CH}_{2}-\mathrm{CH}_{2}\right), 2.96\left(2 \mathrm{H}, \mathrm{t}, J=10.2 \mathrm{~Hz}, \mathrm{CH}_{2}-\right.$ $\left.\mathrm{CH}_{2}-\mathrm{SS}\right), 3.09-3.14\left(1 \mathrm{H}, \mathrm{m}, \mathrm{NH}_{2}-\mathrm{CH}-\mathrm{COO}\right), 3.64\left(2 \mathrm{H}, \mathrm{s}, \mathrm{N}-\mathrm{CH}_{2}-\mathrm{Ar}\right)$, $3.72\left(2 \mathrm{H}, \mathrm{m}, \mathrm{O}-\mathrm{CH}_{2}-\mathrm{CH}_{2}\right), 3.80\left(2 \mathrm{H}, \mathrm{s}, \mathrm{Ar}-\mathrm{CH}_{2}-\mathrm{N}\right), 4.25(2 \mathrm{H}, \mathrm{t}, J=8.4 \mathrm{~Hz}$, $\left.\mathrm{CH}_{2}-\mathrm{CH}_{2}-\mathrm{OCOO}\right), 4.36\left(2 \mathrm{H}, \mathrm{t}, J=9.6 \mathrm{~Hz}, \mathrm{OCOO}-\mathrm{CH}_{2}-\mathrm{CH}_{2}\right), 4.64-4.67$ $(1 \mathrm{H}, \mathrm{m}, \mathrm{O}-\mathrm{CH}), 5.07(1 \mathrm{H}, \mathrm{m}, \mathrm{O}-\mathrm{CH}-\mathrm{O}), 5.30-5.36(1 \mathrm{H}, \mathrm{d}, J=23.6 \mathrm{~Hz}$, $\left.\mathrm{CH}_{2}-\mathrm{CH}=\mathrm{C}\right), 7.43-7.81(11 \mathrm{H}, \mathrm{m}, \mathrm{Ar}-\mathrm{H}) ;{ }^{13} \mathrm{C}-\mathrm{NMR}\left(100.40 \mathrm{MHz}, \mathrm{CDCl}_{3}\right)$ $\delta: 11.84,18.70,18.81,19.28,21.01,22.54,22.80,23.81,24.25,25.04$, $27.67,27.99,28.16,28.20,29.68,31.82,31.87,35.76,36.17,36.55,36.89$. $37.99,39.50,39.70,42.29,49.98,51.89,53.82,56.12,56.66,58.35,58.95$, $52.82,65.61,65.88,75.28,102.80,122.96,125.66,126.02,126.90,127.25$, $127.36,127.66,128.08,128.87,133.29,136.34,143.79,154.90$. HR-FABMS $m / z$ : 1026.5697 (Calcd for $\mathrm{C}_{59} \mathrm{H}_{84} \mathrm{~N}_{3} \mathrm{O}_{8} \mathrm{~S}_{2}\left[\mathrm{M}+\mathrm{H}^{+}\right], 1026.5700$ ).

Synthesis of Cholest-5-en-3-yl (13R)-13-Amino-2-\{4-[(hydroxyamino)carbonyl]benzyl\}-1-(2-naphthyl)-6-oxo-5,7-dioxa-10,11-dithia-2-azatetradecan-14-oate (CCS-K182) A mixture of $5(20.0 \mathrm{mg}, 0.0195 \mathrm{mmol})$ in $\mathrm{CH}_{3} \mathrm{CO}_{2} \mathrm{H}(0.8 \mathrm{ml})$, tetrahydrofuran (THF) $(0.8 \mathrm{ml})$ and $\mathrm{H}_{2} \mathrm{O}(0.2 \mathrm{ml})$ was stirred at $60{ }^{\circ} \mathrm{C}$ for $2.5 \mathrm{~h}$ (Chart 1). Concentration of the reaction mixture, followed by purification of the residue with preparative $\mathrm{SiO}_{2}$ TLC (EtOAc) afforded CCS-K-182 (16 mg, 87\% yield) as a colorless oil. IR (neat) $\mathrm{cm}^{-1}$ : 3400, 3019, 2930, 2855, 1740, 1650, 706. ${ }^{1} \mathrm{H}-\mathrm{NMR}\left(399.65 \mathrm{MHz}, \mathrm{CDCl}_{3}\right)$ $\delta: 0.67-2.01(47 \mathrm{H}, \mathrm{m}), 2.31\left(2 \mathrm{H}, \mathrm{m}, \mathrm{SS}-\mathrm{CH}_{2}-\mathrm{CH}\right), 2.77\left(2 \mathrm{H}, \mathrm{m}, \mathrm{N}-\mathrm{CH}_{2}-\right.$ $\left.\mathrm{CH}_{2}\right), 2.94\left(2 \mathrm{H}, \mathrm{m}, \mathrm{CH}_{2}-\mathrm{CH}_{2}-\mathrm{SS}\right), 3.13\left(1 \mathrm{H}, \mathrm{m}, \mathrm{NH}_{2}-\mathrm{CH}-\mathrm{COO}\right), 3.64(2 \mathrm{H}$, $\left.\mathrm{s}, \mathrm{N}-\mathrm{CH}_{2}-\mathrm{Ar}\right), 3.80\left(2 \mathrm{H}, \mathrm{s}, \mathrm{Ar}-\mathrm{CH}_{2}-\mathrm{N}\right), 4.23\left(2 \mathrm{H}, \mathrm{m}, \mathrm{CH}_{2}-\mathrm{CH}_{2}-\mathrm{OCOO}\right)$, $4.33\left(2 \mathrm{H}, \mathrm{m}, \mathrm{OCOO}-\mathrm{CH}_{2}-\mathrm{CH}_{2}\right), 4.66(1 \mathrm{H}, \mathrm{m}, \mathrm{O}-\mathrm{CH}), 5.34(1 \mathrm{H}, \mathrm{m}$, $\left.\mathrm{CH}_{2}-\mathrm{CH}=\mathrm{C}\right), 7.44-7.82(11 \mathrm{H}, \mathrm{m}, \mathrm{Ar}-\mathrm{H}) .{ }^{13} \mathrm{C}-\mathrm{NMR}\left(100.40 \mathrm{MHz} \mathrm{CDCl}_{3}\right)$ $\delta: 11.86,14.13,18.73,19.30,21.03,22.57,22.70,22.82,23.85,24.28$, $27.67,28.0228 .22,29.37,29.70,31.83,31.89,35.80,36.20,36.55,36.89$, $36.98,37.99,39.53,39.72,42.32,49.98,52.20,56.15,56.67,58.34,59.26$, $65.65,65.76,70.53,75.58,123.02,125.71,126.07,126.95,127.43,127.68$, $128.15,128.92,132.86,133.31,136.35,139.24,144.03,154.91$. HR-FABMS $m / z$ : $942.5115\left(\right.$ Calcd for $\left.\mathrm{C}_{54} \mathrm{H}_{76} \mathrm{~N}_{3} \mathrm{O}_{7} \mathrm{~S}_{2}\left[\mathrm{M}+\mathrm{H}^{+}\right], 942.5125\right)$.

Synthesis of 3-(2-Pyridinyldisulfanyl)propanoic Acid (7) 3-(2Pyridinyldisulfanyl)propanoic acid (7) was synthesized according to the procedure described previously. ${ }^{16)}{ }^{1} \mathrm{H}-\mathrm{NMR}\left(399.65 \mathrm{MHz}, \mathrm{CDCl}_{3}\right) \delta: 2.80(2 \mathrm{H}$, t, $J=6.8 \mathrm{~Hz}), 3.07(2 \mathrm{H}, \mathrm{t}, J=6.8 \mathrm{~Hz}), 7.16(1 \mathrm{H}, \mathrm{ddd}, J=7.8,5.2,1.6 \mathrm{~Hz})$, $7.64(1 \mathrm{H}, \mathrm{dd}, J=7.8,1.6 \mathrm{~Hz}), 7.67(1 \mathrm{H}, \mathrm{dt}, J=7.8,1.6 \mathrm{~Hz}), 8.48(1 \mathrm{H}, \mathrm{dd}$, $J=5.2,1.6 \mathrm{~Hz}$ ).

Synthesis of Distearoylphosphatidylethanolamine (DSPE)-PEG-3-(2pyridyldithio)propanoate (8) To a solution of $7(43 \mathrm{mg}, 0.2 \mathrm{mmol})$ in $\mathrm{CH}_{2} \mathrm{Cl}_{2}(1 \mathrm{ml})$ was added $\mathrm{N}$-hydroxysuccineimide (HOSu, $23 \mathrm{mg}, 0.2 \mathrm{mmol}$ ) and (DCC, $41 \mathrm{mg}, 0.2 \mathrm{mmol}$ ) at $0^{\circ} \mathrm{C}$ and the mixture was stirred at room temperature for $6 \mathrm{~h}$ (Chart 2). After the removal of precipitates by filtration, DSPG-PEG-NH $\mathrm{N}_{2}(50 \mathrm{mg}, \mathrm{ca} .17 .4 \mu \mathrm{mol})$ was added to the solution and stirred for another $18 \mathrm{~h}$ under the same conditions. The reaction mixture was concentrated, applied to Sephadex LH-20 gel filtration column chromatography $(1.5 \mathrm{~cm}$ i.d. $\times 45 \mathrm{~cm})$ and eluted with methanol. The fractions of the eluate from 27 to $32 \mathrm{ml}$ were collected and evaporated in vacuo to gave $\mathbf{8}$ ( $29 \mathrm{mg}, \mathrm{ca} .9 .4 \mu \mathrm{mol}$ ) as a colorless oil. Molecular weights of the components were calculated from electrospray ionization (ESI)-MS (+) multiply charged ion peaks for $2806\left(\mathrm{~m} / \mathrm{z} 936\left(\mathrm{M}+3 \mathrm{H}^{+}\right), 562\left(\mathrm{M}+5 \mathrm{H}^{+}\right)\right), 2850(\mathrm{~m} / \mathrm{z}$ $\left.951\left(\mathrm{M}+3 \mathrm{H}^{+}\right), 713\left(\mathrm{M}+4 \mathrm{H}^{+}\right)\right), 2894\left(\mathrm{~m} / z 966\left(\mathrm{M}+3 \mathrm{H}^{+}\right), 724\left(\mathrm{M}+4 \mathrm{H}^{+}\right)\right.$, $\left.579\left(\mathrm{M}+5 \mathrm{H}^{+}\right)\right), 3026\left(\mathrm{~m} / z 1009\left(\mathrm{M}+3 \mathrm{H}^{+}\right), 757\left(\mathrm{M}+4 \mathrm{H}^{+}\right), 606\left(\mathrm{M}+5 \mathrm{H}^{+}\right)\right)$, $3114\left(\mathrm{~m} / z 1039\left(\mathrm{M}+3 \mathrm{H}^{+}\right), 757\left(\mathrm{M}+4 \mathrm{H}^{+}\right), 624\left(\mathrm{M}+5 \mathrm{H}^{+}\right)\right), 3158(\mathrm{~m} / \mathrm{z} 1054$ $\left.\left(\mathrm{M}+3 \mathrm{H}^{+}\right), 790\left(\mathrm{M}+4 \mathrm{H}^{+}\right)\right), 3202\left(\mathrm{~m} / z 1068\left(\mathrm{M}+3 \mathrm{H}^{+}\right), 641\left(\mathrm{M}+5 \mathrm{H}^{+}\right)\right)$and $3246\left(\mathrm{~m} / \mathrm{z} 1083\left(\mathrm{M}+3 \mathrm{H}^{+}\right), 650\left(\mathrm{M}+5 \mathrm{H}^{+}\right)\right)$, These values corresponded to a 


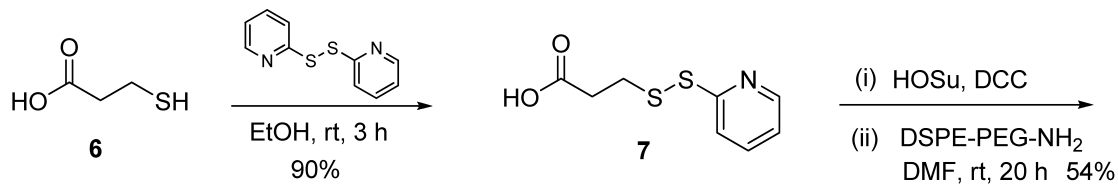<smiles>CCCCCCCCCCCCCCCCCCCCCCCCCC(=O)OCC(COP(=O)([O-])OCCNC(=O)C(C)OCC(C)(C)OCCCNCCCSSc1ccccn1)OCCCCCCC</smiles><smiles>O=C(NOC1CCCCO1)c1ccc(CN(CCO)Cc2ccc3ccccc3c2)cc1</smiles>

(i) triphosgene, DMAP $\mathrm{CH}_{2} \mathrm{Cl}_{2}$, rt, $2 \mathrm{~h}$

(ii) $\mathrm{HO} \sim \mathrm{S}-\mathrm{Mmt}$ (10) (Mmt: 4-monomethoxytrityl) $55 \%$<smiles>NSCCOC(=O)OCCN(Cc1ccc(C(=O)NOC2CCCCO2)cc1)Cc1ccc2ccccc2c1</smiles>

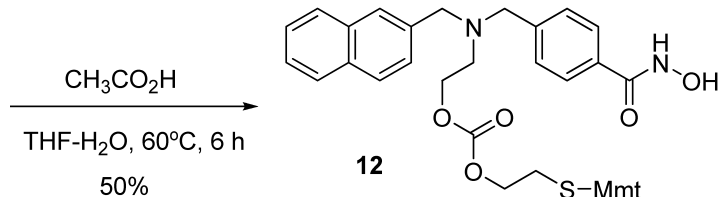

$50 \%$

Chart 2. Synthesis Scheme for DSPE-PEG-K-182

(i) $0.8 \% \mathrm{CF}_{3} \mathrm{CO}_{2} \mathrm{H}, 1 \% \mathrm{Et}_{3} \mathrm{SiH}$, $\mathrm{CH}_{2} \mathrm{Cl}_{2}, 0^{\circ} \mathrm{C}, 3 \mathrm{~h}$

(ii) $8, \mathrm{DMF}, \mathrm{rt}, 10 \mathrm{~h} \quad 83 \%$

\section{DSPE-PEG-K-182}

mass number of $\mathbf{8}$, whose polymerization degrees of PEG were from 40 to 50 .

Synthesis of 2-\{[(4-Methoxyphenyl)(diphenyl)methyl]sulfanyl\}ethanol (10) To a solution of 4-methoxy triphenyl methyl chloride $(2.00 \mathrm{~g}$, $6.4 \mathrm{mmol})$ in $\mathrm{N}, \mathrm{N}$-dimethylformamide (DMF) $(12 \mathrm{ml})$ was added 2-mercaptoethanol $(0.45 \mathrm{ml}, 6.4 \mathrm{mmol})$ and triethylamine $(0.90 \mathrm{ml}, 6.4 \mathrm{mmol})$ and the solution was stirred at room temperature for $3 \mathrm{~h}$ (Chart 2). After the addition of $\mathrm{CHCl}_{3}(30 \mathrm{ml})$, the organic layer was washed with water $(30 \mathrm{ml})$ and then dried over $\mathrm{Na}_{2} \mathrm{SO}_{4}$. Concentration and silica gel column chromatography $($ EtOAc/toluene $=5 / 1)$ gave $\mathbf{1 0}(2.30 \mathrm{~g}, 70 \%)$ as yellow crystals. IR (neat) $\mathrm{cm}^{-1} 3590,1722,1602,1506,1250 ;{ }^{1} \mathrm{H}-\mathrm{NMR}\left(399.65 \mathrm{MHz}, \mathrm{CDCl}_{3}\right) \delta: 2.40$ $(2 \mathrm{H}, \mathrm{t}, J=6.0 \mathrm{~Hz}), 3.31(2 \mathrm{H}, \mathrm{t}, J=6.0 \mathrm{~Hz}), 3.74(3 \mathrm{H}, \mathrm{s}), 6.73(2 \mathrm{H}, \mathrm{d}$, $J=8.4 \mathrm{~Hz}), 7.1-7.5(12 \mathrm{H}, \mathrm{m}) ;{ }^{13} \mathrm{C}-\mathrm{NMR}\left(100.40 \mathrm{MHz} \mathrm{CDCl}_{3}\right) \delta: 35.2$, $55.2,60.8,66.1,113.1,126.7,127.9,129.4,130.7,136.8,145.0,158.1$; HRFAB-MS $m / z$ : 351.1416 (Calcd for $\mathrm{C}_{22} \mathrm{H}_{23} \mathrm{O}_{2} \mathrm{~S}\left[\mathrm{M}+\mathrm{H}^{+}\right]$, 351.1419).

Synthesis of 2-\{[(4-Methoxyphenyl)(diphenyl)methyl]sulfanyl\}ethyl 2[(2-Naphthylmethyl)(4-\{[(tetrahydro-2H-pyran-2-yloxy)amino]carbonbenzyl)amino]ethyl Carbonate (11) To a solution of $\mathbf{9}^{15)}(100 \mathrm{mg}$, $0.23 \mathrm{mmol})$ and DMAP $(169 \mathrm{mg}, 1.38 \mathrm{mmol})$ in $\mathrm{CH}_{2} \mathrm{Cl}_{2}(2.00 \mathrm{ml})$ was added triphosgene $(24 \mathrm{mg}, 0.081 \mathrm{mmol})$ (Chart 2). After stirring at room temperature for $15 \mathrm{~min}, \mathbf{1 0}(80.6 \mathrm{mg}, 0.23 \mathrm{mmol})$ was added and the solution was stirred for another $7 \mathrm{~h}$ under the same conditions. The reaction mixture was diluted with $\mathrm{CHCl}_{3}$, washed with water, and then dried over $\mathrm{Na}_{2} \mathrm{SO}_{4}$. Concentration and preparative thin layer silica gel chromatography $($ EtOAc/hexane $=3 / 2)$ gave $11(102 \mathrm{mg}, 55 \%)$ as a brownish oil. IR (neat) $\mathrm{cm}^{-1}$ 3406, 3026, 2837, 1732, 1685; ${ }^{1} \mathrm{H}-\mathrm{NMR}\left(399.65 \mathrm{MHz}, \mathrm{CDCl}_{3}\right) \delta$ : $1.60-1.87\left(6 \mathrm{H}, \mathrm{m}, 3 \mathrm{CH}_{2}\right.$ of THP), $2.51\left(2 \mathrm{H}, \mathrm{t}, J=6.0 \mathrm{~Hz}, \mathrm{CH}_{2}-\mathrm{CH}_{2}-\mathrm{S}\right)$, $2.77\left(2 \mathrm{H}, \mathrm{m}, \mathrm{N}-\mathrm{CH}_{2}-\mathrm{CH}_{2}\right), 3.65\left(1 \mathrm{H}, \mathrm{m}, \mathrm{O}-\mathrm{CH}_{\mathrm{a}}-\mathrm{CH}_{2}\right.$ of THP), $3.70(2 \mathrm{H}, \mathrm{s}$, $\left.\mathrm{N}-\mathrm{CH}_{2}-\mathrm{Ar}\right), 3.76\left(3 \mathrm{H}, \mathrm{s}, \mathrm{O}-\mathrm{CH}_{3}\right), 3.76\left(2 \mathrm{H}, \mathrm{s}, \mathrm{Ar}-\mathrm{CH}_{2}-\mathrm{N}\right), 3.86(2 \mathrm{H}, \mathrm{t}$, $\left.J=6.0 \mathrm{~Hz}, \mathrm{COO}-\mathrm{CH}_{2}-\mathrm{CH}_{2}\right), 3.98\left(1 \mathrm{H}, \mathrm{m}, \mathrm{O}-\mathrm{CH}_{\mathrm{b}}-\mathrm{CH}_{2}\right.$ of THP), $4.19(2 \mathrm{H}$, t, $\left.J=5.2 \mathrm{~Hz}, \mathrm{CH}_{2}-\mathrm{CH}_{2}-\mathrm{OCOO}\right), 5.06(1 \mathrm{H}, \mathrm{m}, \mathrm{O}-\mathrm{CH}-\mathrm{O}), 6.79(2 \mathrm{H}, \mathrm{d}$, $J=8.0 \mathrm{~Hz}, \mathrm{Ar}-\mathrm{H}), 6.18-7.78(13 \mathrm{H}, \mathrm{m}, \mathrm{Ar}-\mathrm{H}) ;{ }^{13} \mathrm{C}-\mathrm{NMR}(100.40 \mathrm{MHz}$ $\left.\mathrm{CDCl}_{3}\right) \delta: 18.64,25.01,28.05,29.80,30.63,51.75,55.20,58.31,58.81$, $62.66,65.71,66.11,66.45,102.69,113.20,125.61,125.99,126.73,126.86$, $127.21,127.33,127.65,127.94,128.06,128.90,129.42,130.76,132.78$, $133.25,136.36,136.54,143.87,144.81,154.73,158.13,166.05$; HR-FABMS $m / z$ : 811.3425 (Calcd for $\mathrm{C}_{49} \mathrm{H}_{51} \mathrm{~N}_{2} \mathrm{O}_{7} \mathrm{~S}\left[\mathrm{M}+\mathrm{H}^{+}\right], 811.3417$ ).

Synthesis of 2-[\{4-[(Hydroxyamino)carbonyl]benzyl\}(2-naphthylmethyl)amino]ethyl 2-\{[(4-Methoxyphenyl)(diphenyl)methyl]sulfanyl $\}$ ethyl Carbonate (12) A mixture of $11(90 \mathrm{mg}, 0.11 \mathrm{mmol})$ in $\mathrm{CH}_{3} \mathrm{CO}_{2} \mathrm{H}$ $(0.8 \mathrm{ml})$, THF $(0.4 \mathrm{ml})$ and $\mathrm{H}_{2} \mathrm{O}(0.2 \mathrm{ml})$ was stirred at $60^{\circ} \mathrm{C}$ for $6 \mathrm{~h}$ (Chart 2 ). After concentration of the reaction mixture, the resulting crude oil was applied to preparative $\mathrm{SiO}_{2}$ thin layer chromatography $(\mathrm{EtOAc} /$ hexane $=1 / 1)$ for separation to give $\mathbf{1 2}(80.6 \mathrm{mg}, 50 \%)$ as a brownish oil. IR (neat) $\mathrm{cm}^{-1}$ 3400, 3030, 2837, 1741, 1660; ${ }^{1} \mathrm{H}-\mathrm{NMR}\left(399.65 \mathrm{MHz}, \mathrm{CDCl}_{3}\right) \delta: 2.50(2 \mathrm{H}$, m, $\left.\mathrm{CH}_{2}-\mathrm{CH}_{2}-\mathrm{STmt}\right), 2.74\left(2 \mathrm{H}, \mathrm{m}, \mathrm{N}-\mathrm{CH}_{2}-\mathrm{CH}_{2}\right), 3.51-4.00(9 \mathrm{H}, \mathrm{m}$, $\left.\mathrm{Ar}-\mathrm{CH}_{2}-\mathrm{N}, \mathrm{N}-\mathrm{CH}_{2}-\mathrm{Ar}, \mathrm{COO}-\mathrm{CH}_{2}-\mathrm{CH}_{2}, \mathrm{O}-\mathrm{CH}_{3}\right), 4.12(2 \mathrm{H}, \mathrm{t}, J=6.0 \mathrm{~Hz}$, $\left.\mathrm{CH}_{2}-\mathrm{CH}_{2}-\mathrm{OCOO}\right), 6.80-7.77(15 \mathrm{H}, \mathrm{m}, \mathrm{Ar}-\mathrm{H}) ;{ }^{13} \mathrm{C}-\mathrm{NMR}(100.40 \mathrm{MHz}$ $\left.\mathrm{CDCl}_{3}\right) \delta: 29.65,30.67,51.75,55.22,58.23,58.80,65.67,66.15,66.45$, $113.22,125.61,125.99,126.73,126.86,127.31,127.62,126.86,127.31$, $127.62,127.94,129.40,130.74,132.76,133.23,136.52,144.79,154.72$, 158.11, 171.20; HR-FAB-MS $m / z$ : 727.2855 (Calcd for $\mathrm{C}_{44} \mathrm{H}_{43} \mathrm{~N}_{2} \mathrm{O}_{6} \mathrm{~S}$ $\left.\left[\mathrm{M}+\mathrm{H}^{+}\right], 727.2842\right)$.

Synthesis of DSPE-PEG-K-182 To a solution of $12(30 \mathrm{mg}, 0.039$ $\mathrm{mmol})$ in $\mathrm{CH}_{2} \mathrm{Cl}_{2}(2.0 \mathrm{ml})$ was added $\mathrm{CF}_{3} \mathrm{CO}_{2} \mathrm{H}(16 \mu \mathrm{l})$ and $\mathrm{Et}_{3} \mathrm{SiH}(20 \mu \mathrm{l})$ and the solution was stirred at $0{ }^{\circ} \mathrm{C}$ for $4 \mathrm{~h}$ (Chart 2). After confirmation of the complete deprotection of the $p$-methoxytrityl group by TLC, the solution was evaporated to remove the solvent and regents. The residual oily mixture was applied to $8(29 \mathrm{mg}, c a .9 .4 \mu \mathrm{ml})$ in DMF $(0.5 \mathrm{ml})$ and the solution was stirred for another $20 \mathrm{~h}$ at room temperature. The resulting mixture was applied to Sephadex LH-20 column chromatography $(1.5 \mathrm{~cm}$ i.d. $\times 45 \mathrm{~cm})$, eluted with methanol, and the eluate was between 20 and $26 \mathrm{ml}$, in which compounds with an average molecular weight were collected. Evaporation of the solvent gave DSPE-PEG-K-182 $(25 \mathrm{mg}, c a .7 .8 \mu \mathrm{mol})$ as a brownish oil. Molecular weight of the components was calculated from ESI-MS (+) multiply charged ion peaks for $3192\left(\mathrm{~m} / z 1065\left(\mathrm{M}+3 \mathrm{H}^{+}\right), 799\left(\mathrm{M}+4 \mathrm{H}^{+}\right)\right.$, $\left.640\left(\mathrm{M}+5 \mathrm{H}^{+}\right)\right), 3237\left(\mathrm{~m} / z 1080\left(\mathrm{M}+3 \mathrm{H}^{+}\right), 810\left(\mathrm{M}+4 \mathrm{H}^{+}\right), 648\left(\mathrm{M}+5 \mathrm{H}^{+}\right)\right)$, $3325\left(\mathrm{~m} / \mathrm{z} 1109\left(\mathrm{M}+3 \mathrm{H}^{+}\right), 832\left(\mathrm{M}+4 \mathrm{H}^{+}\right), 666\left(\mathrm{M}+5 \mathrm{H}^{+}\right)\right), 3369(\mathrm{~m} / \mathrm{z} 1124$ $\left.\left(\mathrm{M}+3 \mathrm{H}^{+}\right), 843\left(\mathrm{M}+4 \mathrm{H}^{+}\right), 675\left(\mathrm{M}+5 \mathrm{H}^{+}\right)\right), 3545\left(\mathrm{~m} / \mathrm{z} 1183\left(\mathrm{M}+3 \mathrm{H}^{+}\right), 887\right.$ $\left.\left(\mathrm{M}+4 \mathrm{H}^{+}\right), 710\left(\mathrm{M}+5 \mathrm{H}^{+}\right)\right)$and $3589\left(\mathrm{~m} / \mathrm{z} 1197\left(\mathrm{M}+3 \mathrm{H}^{+}\right), 898\left(\mathrm{M}+4 \mathrm{H}^{+}\right)\right.$, $\left.719\left(\mathrm{M}+5 \mathrm{H}^{+}\right)\right)$. These values corresponded to the mass number of DSPEPEG-K-182, whose polymerization degrees of PEG were from 40 to 50.

Synthesis of DSPE-PEG-SAHA To a solution of SAHA ${ }^{17}$ (26 mg, $98 \mu \mathrm{mol})$ in DMF $(0.3 \mathrm{ml})$ was added 3-( $N$-succinimidyloxyglutaryl $)$ aminopropyl, polyethyleneglycol-carbamyldistearoylphosphatidyl-ethanolamine (DSPE-PEG-NHS) $(30 \mathrm{mg}, c a .9 .8 \mu \mathrm{mol})$ and the solution was stirred at room temperature for $12 \mathrm{~h}$. After concentration of the reaction mixture, the residue was applied to Sephadex LH-20 gel filtration column chromatography $(1.5 \mathrm{~cm}$ i.d. $\times 45 \mathrm{~cm})$ and eluted with methanol. The fractions of the eluate from 20 to $28 \mathrm{ml}$ were collected and evaporated in vacuo to gave DSPEPEG-SAHA (21 mg, ca. $9.4 \mu \mathrm{mol})$ as a colorless oil. Molecular weights of the components were calculated from ESI-MS $(+)$ multiply charged ion peaks for $2806\left(\mathrm{~m} / \mathrm{z} 936\left(\mathrm{M}+3 \mathrm{H}^{+}\right), 562\left(\mathrm{M}+5 \mathrm{H}^{+}\right)\right), 2850(\mathrm{~m} / \mathrm{z} 951$ $\left.\left(\mathrm{M}+3 \mathrm{H}^{+}\right), 713\left(\mathrm{M}+4 \mathrm{H}^{+}\right)\right), 2894\left(\mathrm{~m} / z 966\left(\mathrm{M}+3 \mathrm{H}^{+}\right), 724\left(\mathrm{M}+4 \mathrm{H}^{+}\right), 579\right.$ 
$\left.\left(\mathrm{M}+5 \mathrm{H}^{+}\right)\right), 3026\left(\mathrm{~m} / \mathrm{z} 1009\left(\mathrm{M}+3 \mathrm{H}^{+}\right), 757\left(\mathrm{M}+4 \mathrm{H}^{+}\right), 606\left(\mathrm{M}+5 \mathrm{H}^{+}\right)\right)$, $3114\left(\mathrm{~m} / z 1039\left(\mathrm{M}+3 \mathrm{H}^{+}\right), 757\left(\mathrm{M}+4 \mathrm{H}^{+}\right), 624\left(\mathrm{M}+5 \mathrm{H}^{+}\right)\right), 3158(\mathrm{~m} / \mathrm{z} 1054$ $\left.\left(\mathrm{M}+3 \mathrm{H}^{+}\right), 790\left(\mathrm{M}+4 \mathrm{H}^{+}\right)\right), 3202\left(\mathrm{~m} / z 1068\left(\mathrm{M}+3 \mathrm{H}^{+}\right), 641\left(\mathrm{M}+5 \mathrm{H}^{+}\right)\right)$and $3246\left(\mathrm{~m} / z 1083\left(\mathrm{M}+3 \mathrm{H}^{+}\right), 650\left(\mathrm{M}+5 \mathrm{H}^{+}\right)\right)$, These values corresponded to a molecular weight of 13, whose polymerization degrees of PEG were from 40 to 50 .

Synthesis of Oleyl-PEG-SAHA To a solution of SAHA $\left.{ }^{17}\right)(63 \mathrm{mg}$, $0.24 \mathrm{mmol})$ in DMF $(3 \mathrm{ml})$ was added oleyl-PEG-NHS $(100 \mathrm{mg}, c a$. $0.041 \mathrm{mmol}$ ), which was stirred at room temperature for $20 \mathrm{~h}$. After concentration of the reaction mixture, the residue was applied to Sephadex LH-20 gel filtration column chromatography $(1.5 \mathrm{~cm}$ i.d. $\times 45 \mathrm{~cm})$ and eluted with methanol. The fractions of the eluate from 25 to $30 \mathrm{ml}$ were collected and evaporated in vacuo to give oleyl-PEG-SAHA (OL-PEG-SAHA, $107 \mathrm{mg}$, ca. $0.040 \mathrm{mmol}$ ) as a colorless oil. Molecular weights of the components were calculated from ESI-MS (+) multiply charged ion peaks for $2022(\mathrm{~m} / \mathrm{z}$ $\left.1012\left(\mathrm{M}+2 \mathrm{H}^{+}\right), \quad 675\left(\mathrm{M}+3 \mathrm{H}^{+}\right)\right), \quad 2066 \quad\left(\mathrm{~m} / \mathrm{z} \quad 1034 \quad\left(\mathrm{M}+2 \mathrm{H}^{+}\right), 690\right.$ $\left.\left(\mathrm{M}+3 \mathrm{H}^{+}\right)\right), 2110\left(\mathrm{~m} / \mathrm{z} 1056\left(\mathrm{M}+2 \mathrm{H}^{+}\right), 704\left(\mathrm{M}+3 \mathrm{H}^{+}\right)\right), 2154(\mathrm{~m} / \mathrm{z} 1078$ $\left.\left(\mathrm{M}+2 \mathrm{H}^{+}\right), 719\left(\mathrm{M}+3 \mathrm{H}^{+}\right)\right), 2198\left(\mathrm{~m} / \mathrm{z} 1100\left(\mathrm{M}+2 \mathrm{H}^{+}\right), 733\left(\mathrm{M}+3 \mathrm{H}^{+}\right)\right)$, $2242\left(\mathrm{~m} / z 1122\left(\mathrm{M}+2 \mathrm{H}^{+}\right), 748\left(\mathrm{M}+3 \mathrm{H}^{+}\right)\right), 2286\left(\mathrm{~m} / z 1144\left(\mathrm{M}+2 \mathrm{H}^{+}\right), 763\right.$ $\left.\left(\mathrm{M}+3 \mathrm{H}^{+}\right)\right), 2330\left(\mathrm{~m} / \mathrm{z} 1166\left(\mathrm{M}+2 \mathrm{H}^{+}\right), 778\left(\mathrm{M}+3 \mathrm{H}^{+}\right), 583\left(\mathrm{M}+4 \mathrm{H}^{+}\right)\right)$, $2374\left(\mathrm{~m} / z 1188\left(\mathrm{M}+2 \mathrm{H}^{+}\right), 792\left(\mathrm{M}+3 \mathrm{H}^{+}\right), 594\left(\mathrm{M}+4 \mathrm{H}^{+}\right)\right), 2418(\mathrm{~m} / z 1210$ $\left.\left(\mathrm{M}+2 \mathrm{H}^{+}\right), 807\left(\mathrm{M}+3 \mathrm{H}^{+}\right), 605\left(\mathrm{M}+4 \mathrm{H}^{+}\right)\right), 2462\left(\mathrm{~m} / \mathrm{z} 1232\left(\mathrm{M}+2 \mathrm{H}^{+}\right), 822\right.$ $\left.\left(\mathrm{M}+3 \mathrm{H}^{+}\right), 616\left(\mathrm{M}+4 \mathrm{H}^{+}\right)\right)$and $2506\left(\mathrm{~m} / z 1254\left(\mathrm{M}+2 \mathrm{H}^{+}\right), 866\left(\mathrm{M}+3 \mathrm{H}^{+}\right)\right.$, $\left.649\left(\mathrm{M}+4 \mathrm{H}^{+}\right)\right)$. These values corresponded to molecular weight of OLPEG-SAHA, whose polymerization degrees of PEG were from 32 to 45.

Preparation of Liposomal HDACI-Lipid Conjugate Liposomes (L) were prepared from distearoylphosphatidylcholine (DSPC)/cholesterol (Chol) $(55 / 45$, molar ratio) by a modified ethanol injection method, as reported previously. ${ }^{15)}$ For preparation of liposomal cholesteryl HDACI, Chol of liposome (L) formulation was substituted with CCS-K-182, CM-K-182 or CM-SAHA (L-CCS-K-182, L-CM-K-182 and L-CM-SAHA, respectively) (Table 1). For liposomal HDACI-PEG-lipid conjugates, $5 \mathrm{~mol} \%$ of OL$\mathrm{PEG}_{2000}$-SAHA, DSPE-PEG ${ }_{2000}$-SAHA and DSPE-PEG ${ }_{2000}-\mathrm{K}-182$ were added to the formulation of L (L-OL-PEG-SAHA, L-DSPE-PEG-SAHA and L-DSPE-PEG-K-182, respectively) (Table 1). As a control of liposomal HDACI-PEG-lipid conjugates, $5 \mathrm{~mol} \% \mathrm{PEG}_{2000}$-DSPE was added to the formulation of L (L-DSPE-PEG). The particle size distributions and the $\zeta$-potentials were measured by the dynamic light scattering method and the electrophoresis light scattering method, respectively (ELS-Z2; Otsuka Electronics Co., Ltd., Osaka, Japan), at $25^{\circ} \mathrm{C}$ after dispersion and dilution to an appropriate volume with water.

Entrapment Efficiency of HDACI-Lipid Conjugate into Liposome Unencapsulated SAHA-lipid conjugates were removed using a Sephadex G50 column eluted with saline adjusted to $\mathrm{pH}$ 7.4. After purification, the concentration of phospholipid (DSPC) in liposome suspension was measured with the Phospholipids C-test Wako (Wako Pure Chemical Industries, Ltd.). The amount of SAHA-lipid conjugate in liposomes was quantified as its acid hydrolysate, intact SAHA. Quantification of SAHA in the sample and standard mixture was performed with multiple reaction monitoring (MRM) analysis using MS/MS without chromatographic purification. To each of the standard SAHAs or SAHA-lipid conjugates in liposomal suspension $(0.65 \mathrm{ml})$ was added ethanol $(0.25 \mathrm{ml})$ and $12 \mathrm{M} \mathrm{HCl}(0.15 \mathrm{ml})$. After incubating for one hour at $50^{\circ} \mathrm{C}$, the mixture was neutralized to $\mathrm{pH} 7$ with $6 \mathrm{M}$ $\mathrm{NaOH}$ at $0{ }^{\circ} \mathrm{C}$ and extracted twice with ethyl acetate. The organic layer was collected, washed with brine and concentrated. The resulting extract was dissolved in methanol $(0.20 \mathrm{ml})$ to afford a standard or sample solution of SAHA.

For MS/MS analysis, SAHA was analyzed by ESI-LC-MS/MS on a triple- quadrupole mass spectrometer (API-3000; Applied Biosystems). The instrument was operated with a turbo ion spray interface in positive ion mode. Analyst 1.4.1 software (Applied Biosystems) was used to control equipment, data acquisition, and the MRM experiment. The parameters in the method are as follows: dwell time, $1000 \mathrm{~ms}$; MRM transition, $\mathrm{m} / \mathrm{z} 265$ in Q1 and $\mathrm{m} / \mathrm{z}$ 232 in Q3; declustering potential, $45 \mathrm{~V}$; collision energy, $25 \mathrm{~V}$; source temperature, $350{ }^{\circ} \mathrm{C}$ and ion spray voltage, $5000 \mathrm{~V}$. The amount of SAHA in the mixture was determined from the calibration curves constructed from four standards ranging from 0.05 to $1.00 \mu \mathrm{g} / \mathrm{ml}$ of SAHA.

Cell Culture Human cervix epithelial adenocarcinoma HeLa cells were obtained from the European Collection of Cell Culture (Wiltshire, U.K.). Murine colon carcinoma Colon 26 cells were obtained from the Cell Resource Center for Biomedical Research, Tohoku University (Miyagi, Japan). Colon 26 cells were grown in RPMI-1640 medium (Invitrogen, Carlsbad, CA, U.S.A.) and HeLa cells in Eagle's Minimum Essential Medium (Invitrogen), supplemented with $10 \%$ heat-inactivated fetal bovine serum (FBS, Invitrogen) and kanamycin $(100 \mu \mathrm{g} / \mathrm{ml})$ at $37^{\circ} \mathrm{C}$ in a $5 \% \mathrm{CO}_{2}$ humidified atmosphere.

Antiproliferative Activity The cells were seeded in 96-well plates $24 \mathrm{~h}$ prior to transfection. Cells at $30 \%$ confluences in the well were treated with various concentrations of HDACI-lipid conjugates or liposomal HDACIlipid conjugates for $48 \mathrm{~h}$. Cell viability (\%) was measured by WST- 8 assay (Dojindo Laboratories, Kumamoto, Japan) as previously reported. ${ }^{18)}$

Western Blot Analysis Western blot analysis for acetylated histone H3 and $\beta$-actin protein was performed as previously reported. ${ }^{19)}$ Briefly, Colon 26 cells were seeded in a $35-\mathrm{mm}$ culture dish and incubated overnight. The cells at $30 \%$ confluency were treated with liposomal HDACI-lipid conjugates $(10 \mu \mathrm{M}$ as a concentration of HDACI-lipid) or liposomes (L or LDSPE-PEG) and then incubated for $24 \mathrm{~h}$. The cells were suspended in lysis buffer (1\% Triton-X 100 in phosphate-buffered saline pH 7.4 (PBS)), and then Western blotting was performed as previously reported. ${ }^{19)}$ Acetylated histone $\mathrm{H} 3$ was identified using rabbit anti-acetyl histone $\mathrm{H} 3$ antibody (Sigma Chemical Co., St. Louis, MO, U.S.A.) and goat anti-rabbit immunoglobulin G (IgG) peroxidase conjugate (Santa Cruz Biotechnology, Santa Cruz, CA, U.S.A.) as the secondary antibody. The blots of $\beta$-actin protein were probed with a mouse anti $\beta$-actin IgG peroxidase conjugate ( $\beta$-actin (C4) HRP; Santa Cruz Biotechnology).

Caspase 3/7 Activities Colon 26 cells were seeded in a $35-\mathrm{mm}$ culture dish and incubated overnight. The cells at $30 \%$ confluences in the well were treated with liposomal HDACI-lipid conjugates for $24 \mathrm{~h}$. To measure caspase 3/7 activity, a homogenous assay (Caspase-Glo ${ }^{\text {TM }} 3 / 7$ assay; Promega, Madison, WI, U.S.A.) was performed as previously reported. ${ }^{18)}$

Statistical Analysis Significant differences in the mean values were evaluated by Student's unpaired $t$-test. A $p$ value of 0.05 or less was considered significant.

\section{Results and Discussion}

SAHA is orally administrated because of its hydrophobic property, and is easily metabolized in the liver ${ }^{12,13}$; therefore, we decided to incorporate a potent hydroxamic acid, HDACI, SAHA or K-182, ${ }^{15)}$ into the liposomal membrane to allow their intravenous administration and increase their acculturation in the tumor by the EPR effect. Liposomal HDACI formulation warrants in vivo experiment; however, the amount of hydrophobic drugs incorporated into liposomal membrane was limited. Therefore, we decided to synthesize HDACI-

Table 1. Formulation, Particle Size and $\zeta$-Potential of Liposomal HDACI-Lipid Conjugates

\begin{tabular}{|c|c|c|c|c|}
\hline Liposome & Formulation (mol\% ratio) & Size $(\mathrm{nm})$ & Polydispersity index & $\begin{array}{c}\zeta \text {-Potential } \\
\quad(\mathrm{mV})\end{array}$ \\
\hline $\mathrm{L}$ & DSPC/Chol $(55: 45)$ & 138.9 & 0.28 & $1.9 \pm 1.1$ \\
\hline L-CM-SAHA & DSPC/CM-SAHA $(55: 45)$ & 981.5 & 0.35 & $18.5 \pm 1.2$ \\
\hline L-CM-K-182 & DSPC/CM-K-182 (55:45) & 311.1 & 0.16 & $26.4 \pm 1.6$ \\
\hline L-CCS-K-182 & DSPC/CCS-K-182 $(55: 45)$ & 153.8 & 0.20 & $36.3 \pm 0.5$ \\
\hline L-DSPE-PEG & DSPC/Chol/DSPE-PEG ${ }_{2000}(52: 43: 5)$ & 86.6 & 0.26 & $-63.4 \pm 2.9$ \\
\hline L-DSPE-PEG-SAHA & DSPC/Chol/DSPE-PEG 2000 -SAHA $(52: 43: 5)$ & 110.5 & 0.13 & $-43.6 \pm 1.6$ \\
\hline L-OL-PEG-SAHA & DSPC/Chol/OL-PEG 2000 -SAHA $(52: 43: 5)$ & 131.2 & 0.16 & $-31.6 \pm 2.9$ \\
\hline L-DSPE-PEG-K-182 & DSPC/Chol/DSPE-PEG $_{2000}-\mathrm{K}-182(52: 43: 5)$ & 90.2 & 0.23 & $-29.8 \pm 0.4$ \\
\hline
\end{tabular}

L: Liposome. 
lipid conjugates to increase the amount of HDACI incorporated into the liposomal membrane.

Accordingly, we designed lipid conjugates of SAHA and $\mathrm{K}-182$, in which their hydroxyl $(\mathrm{OH})$ group is tethered to an aliphatic fatty acid or a cholesteryl group via linkers connected with biodegradable ester or disulfide carbonate bonds (Fig. 1). The disulfide carbonate linker in a cholesteryl K182, CCS-K-182, and a $\mathrm{PEG}_{2000}$-lipid conjugate of $\mathrm{K}-182$, DSPE-PEG-K-182, is designed to release unmodified K-182 in the reductive cytosolic condition. ${ }^{15)}$ We synthesized these compounds using the procedures shown in Charts 1 and 2 . The cholesteryl group of CM-K-182 and CM-SAHA is linked with succinic diester bonds, formed by coupling cholesteryl succinate to the original HDACIs, as described previously. ${ }^{15)}$ The PEG $_{2000}$-lipid conjugates of SAHA, DSPEPEG-SAHA and OL-PEG-SAHA, were furnished with a reaction between SAHA and commercially available $N$-hydroxysuccinimide (NHS) ester of DSPE-PEG 2000 or oleyl-PEG 2000 followed by purification with LH-20 gel filtration column chromatography.

For preparation of liposomal HDACI-lipid conjugates, the formulation of DSPC/Chol (L) or DSPC/Chol/DSPE$\mathrm{PEG}_{2000}$ (L-DSPE-PEG), which was often used for in vivo experiments, ${ }^{20-22)}$ was modified by substitution of a component (Chol in L or DSPE-PEG 2000 in L-DSPE-PEG) with HDACI-lipid conjugate. For preparation of liposomal HDACI-Chol conjugate, Chol of liposome (L) formulation was substituted with CCS-K182, CM-K182 and CM-SAHA (L-CCS-K-182, L-CM-K-182 and L-CM-SAHA, respectively) (Table 1). For liposomal HDACI-PEG-lipid conjugates, DSPE-PEG ${ }_{2000}$ of L-DSPE-PEG formulation was substituted with OL-PEG-SAHA, DSPE-PEG-SAHA and DSPE-PEG-K-182 (L-OL-PEG-SAHA, L-DSPE-PEG-
SAHA and L-DSPE-PEG-K-182, respectively) (Table 1). The liposomal HDACI-PEG-lipid conjugates were about $90-130 \mathrm{~nm}$ with narrow size dispersions and negative $\zeta$-potentials, which might be influenced by PEG coating (Table 1). The liposomal HDACI-Chol conjugates, L-CM-K-182 and L-CCS-K-182 were about $150-300 \mathrm{~nm}$, but L-CMSAHA was large (about $1 \mu \mathrm{m}$ ) (Table 1). Among liposomal HDACI-Chol conjugates, L-CCS-K-182 and L-CM-K-182 had positive charges in $\zeta$-potential, which might be affected by a ternary amine of K-182. When size and $\zeta$-potential measurements were conducted over a period of one month at $4{ }^{\circ} \mathrm{C}$, no physicochemical changes were observed. After gel filtration, we measured the entrapment efficiency of HDACIlipid conjugate into the liposome. Entrapment efficiency of HADCI-Chol conjugates into liposomes was almost 100\%, but that of HDACI-PEG-lipid conjugates was about 60 $70 \%$ (data not shown), suggesting that the lipid anchor of HDACI-lipid conjugate might affect modification of the surface of liposomes by HDAC-lipid; however, in subsequent experiments, we used unpurified liposomes for uniform lipid concentration among liposomal HDACI-lipids.

To investigate whether liposomal HDACI-lipid conjugates had antitumor effects on tumor cells, we treated HDACI-lipid conjugates or liposomal HDACI-lipid conjugates with HeLa and Colon 26 cells for $48 \mathrm{~h}$ (Table 2). In HDACI-lipid conjugates, CCS-K-182, DSPE-PEG-K-182, DSPE-PEG-SAHA and OL-PEG-SAHA showed high cytotoxicity for both cell lines, but CM-K-182 and CM-SAHA only weakly. In liposomal HDACI-lipid conjugates, L-OL-PEG-SAHA strongly exhibited cytotoxicity for Colon 26 and HeLa cells $\left(\mathrm{IC}_{50}=1.4\right.$, $4.0 \mu \mathrm{M}$, respectively), L-DSPE-PEG-SAHA, L-DSPE-PEGK-182 and L-CCS-K-182 moderately for HeLa cells $\left(\mathrm{IC}_{50}=13.3,9.9,3.5 \mu \mathrm{M}\right.$, respectively), but L-CM-SAHA and

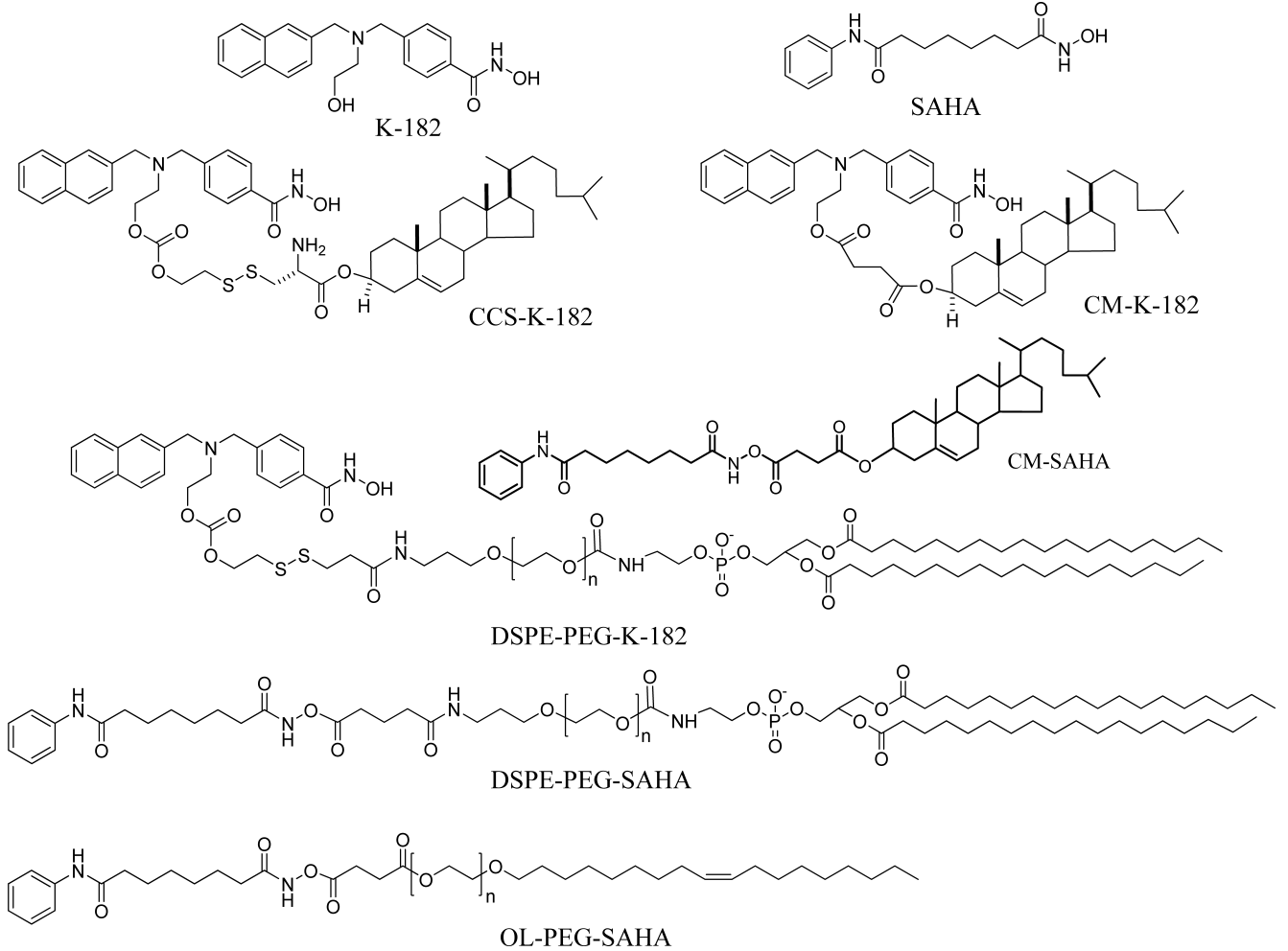

Fig. 1. Chemical Structures of K-182, SAHA, K-182 and SAHA Derivatives 
Table 2. $\mathrm{IC}_{50}$ Values for HeLa and Colon 26 Cells by HDACI-Lipid Conjugates and Liposomal HDACI-Lipid Conjugates

\begin{tabular}{|c|c|c|c|c|}
\hline \multirow[t]{2}{*}{ Drugs } & \multicolumn{2}{|c|}{$\begin{array}{c}\mathrm{IC}_{50} \text { of HDACI or HDACI- } \\
\text { lipid conjugates }(\mu \mathrm{M})\end{array}$} & \multicolumn{2}{|c|}{$\begin{array}{l}\mathrm{IC}_{50} \text { of liposomal HDACI- } \\
\text { lipid conjugates }(\mu \mathrm{M})\end{array}$} \\
\hline & $\mathrm{HeLa}$ & Colon 26 & $\mathrm{HeLa}$ & Colon 26 \\
\hline SAHA & 1.9 & 9.5 & - & - \\
\hline K-182 & 1.0 & 2.3 & - & - \\
\hline CM-SAHA & 19.0 & $>40.0$ & 18.6 & $>40.0$ \\
\hline CM-K-182 & 27.4 & $>40.0$ & $>40.0$ & $>40.0$ \\
\hline CCS-K-182 & 4.6 & 17.1 & 3.5 & 19.4 \\
\hline DSPE-PEG-SAHA & 7.6 & 10.7 & 13.3 & $>20.0$ \\
\hline OL-PEG-SAHA & 1.8 & 2.4 & 1.4 & 4.0 \\
\hline DSPE-PEG-K-182 & 5.1 & 7.8 & 9.9 & $>20.0$ \\
\hline
\end{tabular}

$\mathrm{IC}_{50}$ was calculated as a concentration of HDACI or HDACI-lipid conjugate.

L-CM-K-182 did not (Table 2). In particulars, L-OL-PEGSAHA showed higher cytotoxicity than free SAHA for both cell lines $\left(\mathrm{IC}_{50}\right.$ of free $\mathrm{SAHA}=1.9,9.5 \mu \mathrm{M}$ for HeLa and Colon 26 cells, respectively), suggesting that hydroxamic acid of SAHA might be protected from hydrolysis in the medium by conjugation with lipid. When L and L-DSPEPEG were treated at the same lipid concentrations with liposomal HDACI-lipid conjugates, they did not show any cytotoxic effects (data not shown). Generally, positively charged liposomes can be easily taken up by the cells via electrostatic interaction compared with negatively charged ones, however, cytotoxicties by liposomal HDACI-lipid conjugates were not affected by the physicochemical property and were dependent on structure of HDACI-lipid conjugates.

Histone $\mathrm{H} 3$ is one of the core histone proteins in the chromatin of eukaryotic cells. Hyperacetylation of lysine residues, i.e. lysine 9 , in the N-terminal tails of histone $\mathrm{H} 3$ loosens the histone-DNA binding and activates gene transcription. On the other hand, deacetylation of acetylated lysine residues leads to tight histone-DNA binding, which restricts the access of transcriptional factors. Histone acetyltransferases (HATs) and HDACs play a crucial role in this reversible acetylation and deacetylation of histones regulating gene expression. Inhibition of HDACs therefore induces histone hyperacetylation and activates gene transcription. ${ }^{23)}$ SAHA selectively induces the expression of specific genes such as $\mathrm{p} 21^{\mathrm{WAF} 1 / \mathrm{CIP} 1}$ cyclin-dependent kinase inhibitor to effect cell-cycle arrest, resulting in the induction of apoptosis. $^{24)}$

We evaluated the acetylation of histone $\mathrm{H} 3$ and induction of apoptosis by liposomal HDACI-lipid conjugates (Fig. 2). When liposomal HDACI-lipid conjugates were treated with Colon 26 cells for $24 \mathrm{~h}$, L-CCS-K-182, L-DSPE-PEG-SAHA and L-OL-PEG-SAHA strongly induced the acetylation of histone H3 (Fig. 2A). Furthermore, to examine the effect of histone hyperacetylation on the activity of apoptosis-associated enzymes, we measured caspase $3 / 7$ activity $24 \mathrm{~h}$ after treatment with liposomal HDACI-lipid conjugates at $10 \mu \mathrm{M}$ as a concentration of K-182 or SAHA (Fig. 2B). Among the liposomal HDACI-lipid conjugates, L-OL-PEG-SAHA strongly increased caspase $3 / 7$ activities about 3 -fold higher than untreated cells. In L-CCS-K-182, the caspase 3/7 activity was not increased because CCS-K-182 concentration in the medium was under the $\mathrm{IC}_{50}$ for Colon 26 cells $(19.4 \mu \mathrm{M})$. This observation indicated that L-OL-PEG-SAHA could effi-

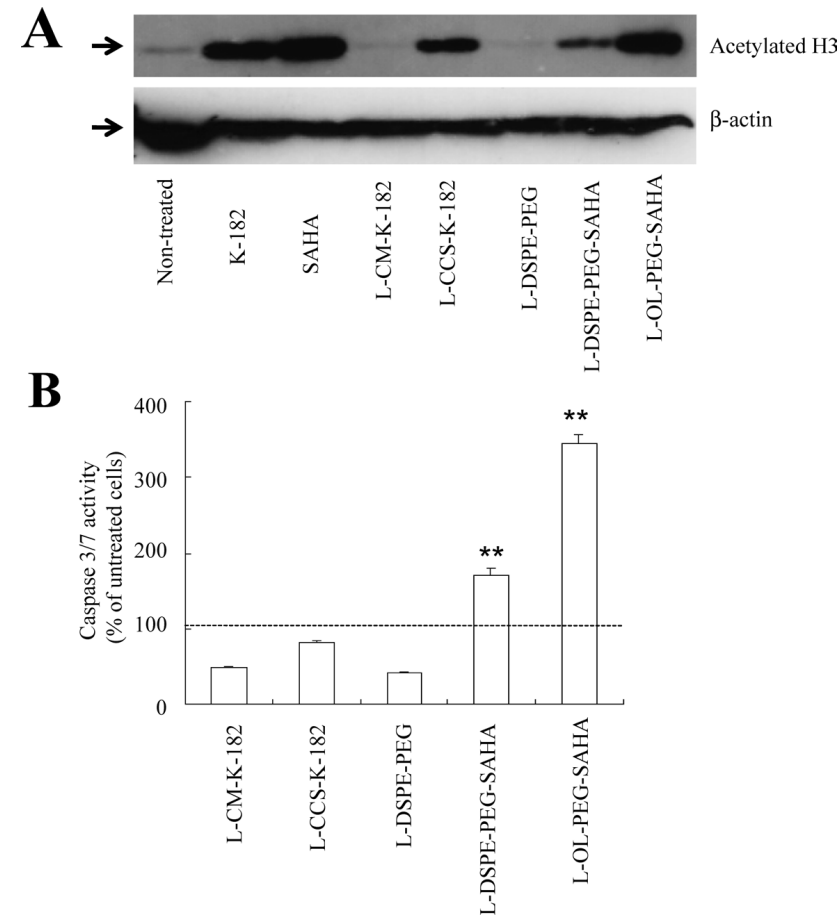

Fig. 2. Acetylation of Core Histone H3 Protein (A) and Induction of Caspase 3/7 Activity (B) by Liposomal HDACI-Lipid Conjugates in Colon 26 Cells

The cells were treated with a medium containing liposomal HDACI-lipid conjugates or free HDACIs. L-DSPE-PEG and L were treated at the same lipid concentration of liposomal HDACI-lipid conjugations. In (A), after $24 \mathrm{~h}$ incubation in the medium, cellular proteins were isolated from the cells and resolved on $12.5 \%$ SDS-PAGE $(10 \mu \mathrm{g}$ protein in each well), followed by Western blot analysis for acetylated histone H3 protein and $\beta$-actin. In (B), after $48 \mathrm{~h}$ incubation in the medium, caspase $3 / 7$ activity in Colon 26 cells was measured. Each column shows the mean \pm S.D. $(n=3)$. $* * p<0.01$, compared with untreated cells.

ciently release SAHA in the cells and inhibit HDAC in the nucleus, resulting in the hyperacetylation of histone $\mathrm{H} 3$.

In antitumor activity, L-CCS-K-182 had antitumor activity via acetylation of histone H3, but L-CM-K-182 and L-CMSAHA did not, suggesting that the disulfide carbonate bond between HDACI and Chol was easily cleavable in cytoplasm, but the ester bond was not. In contrast, L-DSPE-PEGSAHA, L-DSPE-PEG-K-182 and L-OL-PEG-SAHA had tumor suppressive effects on HeLa cells, indicating that $\mathrm{K}$ 182 or SAHA on the PEG-terminal of PEG-lipid via a carbamide bond was cleavable in the cells. Among the liposomal HDACI-lipid conjugates, L-OL-PEG-SAHA showed the highest antitumor effect on both HeLa and Colon 26 cells. DSPE-PEG-SAHA was anchored in liposomes via two alkyl chains, which could be easily retained liposome compared to OL-PEG-SAHA, which was anchored via one alkyl chain. Previously, we synthesized K-182-lipid conjugate, which bound to lipid via a carbamide or disulfide linker, into cationic nanoparticles and confirmed that the conjugates were activated by cleavage between K-182 and lipid. ${ }^{15}$ ) Therefore, OL-PEG-SAHA might be efficiently released from L-OL-PEG-SAHA in the cells, and converted to SAHA by the cleavage of carbamide bond. However, it was not clear why L-OL-PEG-SAHA could induce higher cytotoxicity than free SAHA, but OL-PEG-SAHA might be stabilized hydroxamic acid by conjugation with PEG-lipid. We confirmed that oleyl-PEG ${ }_{2000}$ did not show cytotoxicity at the concentra- 
tions used in this study (data not shown).

Liposomes take advantage of the EPR effect for increasing their tumor accumulation when they are intravenously injected. ${ }^{14)}$ Liposomal HDACI-lipid conjugates might improve the pharmacokinetic and pharmacodistribution of the encapsulated drug. Liposomal LAQ824, hydrophilic hydroxamic acid HDAC inhibitor, was shown to be both long-circulating and highly stable in vivo. ${ }^{14)}$ In further study, we need to evaluate whether liposomal HDACI-lipid conjugation has antitumor effects by intravenous injection. Liposomal HDACIlipid conjugates might have potential as an effective vector in cancer therapy.

In this study, we synthesized HDACI-lipid conjugates and applied liposomal formulations. Liposomal HDACI-lipid conjugates could induce antitumor activity via acetylation of histone $\mathrm{H} 3$ and activation of caspase 3/7 in HeLa and Colon 26 tumor cells. These findings indicate that liposomal HDACI-lipid conjugates have potential as an effective vector in cancer therapy.

Acknowledgements This project was supported in part by a Grant-inAid for Scientific Research (C) from the Ministry of Education, Culture, Sports, Science, and Technology of Japan, KAKENHI (21590131), and by the Open Research Center Project.

\section{References}

1) Nightingale K. P., O’Neill L. P., Turner B. M., Curr. Opin. Genet. Dev., 16, 125-136 (2006).

2) Wade P. A., Pruss D., Wolffe A. P., Trends Biochem. Sci., 22, 128 132 (1997).

3) Marchion D., Münster P., Expert Rev. Anticancer Ther., 7, 583-598 (2007).

4) Elaut G., Török G., Vinken M., Laus G., Papeleu P., Tourwe D., Rogiers V., Drug Metab. Dispos., 30, 1320-1328 (2002).

5) Vanhaecke T., Papeleu P., Elaut G., Rogiers V., Curr. Med. Chem., 11, 1629 -1643 (2004).

6) Marks P., Rifkind R. A., Richon V. M., Breslow R., Miller T., Kelly W.
K., Nat. Rev. Cancer, 1, 194-202 (2001).

7) Butler L. M., Agus D. B., Scher H. I., Higgins B., Rose A., CordonCardo C., Thaler H. T., Rifkind R. A., Marks P. A., Richon V. M., Cancer Res., 60, 5165-5170 (2000).

8) Richon V. M., Webb Y., Merger R., Sheppard T., Jursic B., Ngo L., Civoli F., Breslow R., Rifkind R. A., Marks P. A., Proc. Natl. Acad. Sci. U.S.A., 93, 5705-5708 (1996).

9) Heymann W. R., J. Am. Acad. Dermatol., 59, 696-697 (2008).

10) Vansteenkiste J., Van Cutsem E., Dumez H., Chen C., Ricker J. L., Randolph S. S., Schöffski P., Invest. New Drugs, 26, $483-488$ (2008).

11) Luu T. H., Morgan R. J., Leong L., Lim D., McNamara M., Portnow J., Frankel P., Smith D. D., Doroshow J. H., Wong C., Aparicio A., Gandara D. R., Somlo G., Clin. Cancer Res., 14, 7138-7142 (2008).

12) Du L., Musson D. G., Wang A. Q., Rapid Commun. Mass Spectrom., 19, 1779-1787 (2005)

13) Kelly W. K., Richon V. M., O’Connor O., Curley T., MacGregorCurtelli B., Tong W., Klang M., Schwartz L., Richardson S., Rosa E., Drobnjak M., Cordon-Cordo C., Chiao J. H., Rifkind R., Marks P. A., Scher H., Clin. Cancer Res., 9, 3578-3588 (2003).

14) Drummond D. C., Marx C., Guo Z., Scott G., Noble C., Wang D., Pallavicini M., Kirpotin D. B., Benz C. C., Clin. Cancer Res., 11, 3392-3401 (2005).

15) Ishii Y., Hattori Y., Yamada T., Uesato S., Maitani Y., Nagaoka Y., Eur. J. Med. Chem., 44, 4603-4610 (2009).

16) Xie H., Braha O., Gu L. Q., Cheley S., Bayley H., Chem. Biol., 12, 109-120 (2005).

17) Gediya L. K., Chopra P., Purushottamachar P., Maheshwari N., Njar V. C., J. Med. Chem., 48, 5047-5051 (2005).

18) Hattori Y., Hakoshima M., Koga K., Maitani Y., Int. J. Oncol., 36, 1039-1046 (2010)

19) Hattori Y., Fukushima M., Maitani Y., Int. J. Oncol., 30, 1427-1439 (2007).

20) Parr M. J., Masin D., Cullis P. R., Bally M. B., J. Pharmacol. Exp. Ther, 280, 1319-1327 (1997).

21) Hattori Y., Shi L., Ding W., Koga K., Kawano K., Hakoshima M., Maitani Y., J. Controlled Release, 136, 30-37 (2009).

22) Hong R. L., Huang C. J., Tseng Y. L., Pang V. F., Chen S. T., Liu J. J., Chang F. H., Clin. Cancer Res., 5, 3645-3652 (1999).

23) Strahl B. D., Allis C. D., Nature (London), 403, $41-45$ (2000).

24) Richon V. M., Sandhoff T. W., Rifkind R. A., Marks P. A., Proc. Natl. Acad. Sci. U.S.A., 97, 10014-10019 (2000). 